\title{
Impact of diabetes mellitus on in-hospital mortality in adult patients with COVID-19: a systematic review and meta-analysis
}

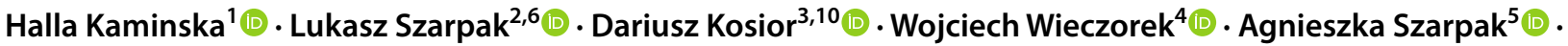

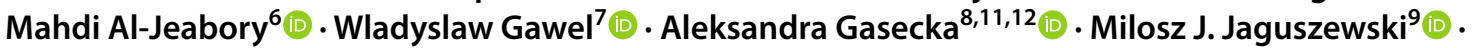 \\ Przemyslawa Jarosz-Chobot ${ }^{1}$ [D
}

Received: 30 December 2020 / Accepted: 3 March 2021 / Published online: 20 March 2021

๑) Springer-Verlag Italia S.r.l., part of Springer Nature 2021

\begin{abstract}
Background The novel coronavirus disease 2019 (COVID-19) has spread worldwide since the beginning of 2020, placing the heavy burden on the health systems all over the world. The population that particularly has been affected by the pandemic is the group of patients suffering from diabetes mellitus. Having taken the public health in considerations, we have decided to perform a systematic review and meta-analysis of diabetes mellitus on in-hospital mortality in patients with COVID-19. Methods A systematic literature review (MEDLINE, EMBASE, Web of Science, Scopus, Cochrane) including all published clinical trials or observational studies published till December 10, 2020, was performed using following terms "diabetes mellitus" OR “diabetes" OR "DM" AND “survival” OR "mortality” AND "SARS-CoV-2" OR "COVID-19”.

Results Nineteen studies were included out of the 7327 initially identified studies. Mortality of DM patients vs non-DM patients was 21.3 versus $6.1 \%$, respectively $(\mathrm{OR}=2.39 ; 95 \% \mathrm{CI}: 1.65,3.64 ; P<0.001)$, while severe disease in DM and non-DM group varied and amounted to $34.8 \%$ versus $22.8 \%(\mathrm{OR}=1.43 ; 95 \% \mathrm{CI}: 0.82,2.50 ; P=0.20)$. In the DM group, the complications were observed far more often when compared with non-DM group, both in acute respiratory distress $(31.4$ vs. $17.2 \%$; OR $=2.38 ; 95 \% \mathrm{CI}: 1.80,3.13 ; P<0.001)$, acute cardiac injury $(22.0 \%$ vs. $12.8 \%$; OR $=2.59 ; 95 \% \mathrm{CI}: 1.81,3.73$; $P<0.001)$, and acute kidney injury (19.1 vs. $10.2 \%$; OR $=1.97 ; 95 \% \mathrm{CI}: 1.36,2.85 ; P<0.001)$.

Conclusions Based on the findings, we shall conclude that diabetes is an independent risk factor of the severity of COVID-19 in-hospital settings; therefore, patients with diabetes shall aim to reduce the exposure to the potential infection of COVID-19.
\end{abstract}

Keywords Diabetes mellitus $\cdot$ COVID-19 $\cdot$ SARS-CoV-2 $\cdot$ Systematic review $\cdot$ Meta-analysis $\cdot$ Mortality $\cdot$ Hospitalization

Managed By Antonio Secchi.

Lukasz Szarpak

lukasz.szarpak@gmail.com

1 Department of Pediatrics and Children's Diabetology, Faculty of Medical Sciences in Katowice, Medical University of Silesia, Silesia, Poland

2 Maria Sklodowska-Curie Bialystok Oncology Center, Ogrodowa 12 str., 15-027, Bialystok, Poland

3 Faculty of Medicine, Collegium Medicum, Cardinal Stefan Wyszynski University, Warsaw, Poland

4 Department of Emergency Medicine, Medical University of Warsaw, Warsaw, Poland

5 Maria Sklodowska-Curie Medical Academy in Warsaw, Warsaw, Poland

6 Polish Society of Disaster Medicine, Warsaw, Poland
7 Department of Surgery, The Silesian Hospital in Opava, Opava, Czech Republic

8 Department of Cardiology, University Medical Center Utrecht, Utrecht, The Netherlands

9 First Department of Cardiology, Medical University of Gdansk, Gdansk, Poland

10 Department of Cardiology and Hypertension With Electrophysiological Lab, Central Clinical Hospital of the Ministry of the Interior and Administration in Warsaw, Warsaw, Poland

11 Laboratory of Experimental Clinical Chemistry, Amsterdam University Medical Center, Amsterdam, The Netherlands

12 1St Chair and Department of Cardiology, Medical University of Warsaw, Warsaw, Poland 


\section{Introduction}

In 2020, world has been facing 2 pandemics. The new one has started in January 2020 with the outbreak of coronavirus disease 2019 (COVID-19) caused by a severe acute respiratory syndrome coronavirus 2 (SARS-CoV-2) [1]. The COVID-19 started in Wuhan, China as has rapidly spread through the whole globe causing patients to suffer viral pneumonia like symptoms [2]. No specific treatment has been found so far; however, a treatment with antiviral agents has been proposed, yet with no efficiency [3]. Currently, the only way to truly limit the spread of the disease is the widespread use of vaccinations [4]. On the other hand, the pandemic that the world is fighting every year is the diabetes, which is the only non-infectious disease declared pandemic by the United Nations [5]. Diabetes causes the immunosuppression which leaves patients more prone to the infectious complications [6]. Those two pandemics go hand to hand as literature confirms that most people who suffer from COVID-19 also have comorbidities, most common being diabetes, cardiovascular disease, and hypertension [7]. Additionally, diabetes has been found to increase complications and mortality rate in COVID-19 infected patients [8]. Taking the aforementioned arguments regarding public health, we have decided to perform systematic review and meta-analysis aim to summarize and synthesize the evidence published about the impact of diabetes mellitus on in-hospital mortality in patients with COVID-19.

This systematic review and meta-analysis aim to summarize and synthesize the evidence published about the impact of diabetes mellitus on in-hospital mortality in patients with COVID-19.

\section{Methods}

The Systematic Review and Meta-analysis were conducted in accordance with the Preferred Reporting Items for Systematic Reviews and Meta-Analyses (PRISMA) statement [9].

\section{Search strategy}

Two investigators (H.K. and M.P.) independently searched for published clinical trials or observational studies indexed in MEDLINE, EMBASE, Web of Science, Scopus and the Cochrane databases from inception to December 10, 2020, using the following terms: "diabetes mellitus" OR "diabetes" OR "DM" AND "survival" OR "mortality"
AND "SARS-CoV-2" OR “COVID-19”. We limited the search to English-language studies. A manual search for additional pertinent studies and review articles using references from the retrieved articles was also completed.

\section{Inclusion criteria and exclusion criteria}

The PECOS strategy consisting of patient, exposure, comparison, and outcome was used as a tool to ensure focused clinical questions. The prespecified criteria for studies included in the meta-analysis were original papers of RCTs or cohort studies with minimum 10 patients in each group of $(\mathrm{P})$ participants, adult patients with diabetes mellitus; (E) COVID-19 disease; (C) patients without diabetes mellitus; $(\mathrm{O})$ outcomes, detailed information for survival, complications and length of hospital stay; (S) study design, randomized controlled trials, quazi-randomized or observational studies comparing resuscitation effects in patients with cardiac arrest.

Studies were excluded if they were reviews, case reports, conference or poster abstracts or articles not containing original data or comparator group.

\section{Data extraction}

The titles and abstracts were screened for relevance by 2 of the authors (L.S. and H.K.) independently. Any disagreement was resolved by discussion with third investigator (M.J.J.).

The manuscripts of selected titles/abstracts were assessed for inclusion, and the authors were contacted if further information was required.

Using the selection criteria enlisted above, the three reviewers (L.S., H.K. and W.W.) independently identified the papers to be included and excluded, and data from the included papers were extracted using predefined extraction flow sheets, and discrepancies were resolved through consensus with another reviewer (M.J.J.).

\section{Quality assessment}

Two investigators (H.K. and L.S.) independently extracted individual study data and evaluated studies for risk of bias using a previously piloted standardized form and the Newcastle-Ottawa scale [10]. The three major domains of quality of a study covered by this tool were selection of participants, comparability of cohorts, and outcome assessment against a total score of 9. Any disagreement was resolved by discussion with third investigator (J.S.). 


\section{Statistical analysis}

Statistical analysis was performed with Review Manager (RevMan) software, version 5.4 (Cochrane Collaboration, Oxford, UK). The Mantel-Haenszel method was used to analyze dichotomous outcomes, and results are reported as odds ratios (ODs) with 95\% confidence interval (CI) and two tailed $\mathrm{p}$ values. Continuous outcome differences were analyzed using an inverse variance model with a 95\%CI, and values are reported as mean difference (MD). Results are presented as risk ratios (RR) with $95 \%$ confidence intervals (CI) for dichotomous measures. When the continuous outcome was reported in a study as median, range, and interquartile range, we estimated means and standard deviations using the formula described by Hozo et al. [11]. We quantified heterogeneity in each analysis by the tau-squared and I-squared statistics. Heterogeneity was detected with the chi-squared test with $\mathrm{n}-1$ degrees of freedom, which was expressed as $I^{2}$. Values of $I^{2}>50 \%$ and $>75 \%$ were considered to indicate moderate and significant heterogeneity among studies, respectively. A P value less than 0.05 was judged statistically significant.

\section{Role of the funding source}

This study was not supported by any funding source.

\section{Results}

\section{Description of studies included in the analysis}

We identified 7,327 records through the literature search and 1 record from the reference list of relevant articles. Among them, 19 studies fulfilled our inclusion and exclusion criteria [12-31]. The identification procedure of these eligible articles is described in Fig. 1. The studies examined 10,801 patients.

\section{Characteristics of selected studies}

Table 1 gives details of the study characteristics. All studies were retrospective studies. Fourteen studies reported the outcome of mortality, and seven studies reported the outcome of length of hospital stay. Of the 19 studies, 10
Fig. 1 Flow diagram showing stages of database searching and study selection as per PRISMA guidelines
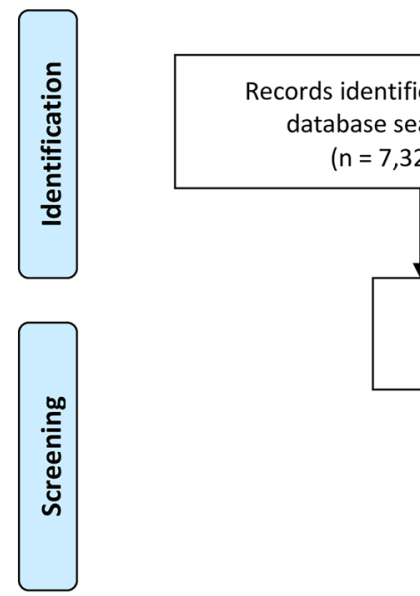

Records after duplicates removed $(n=355)$

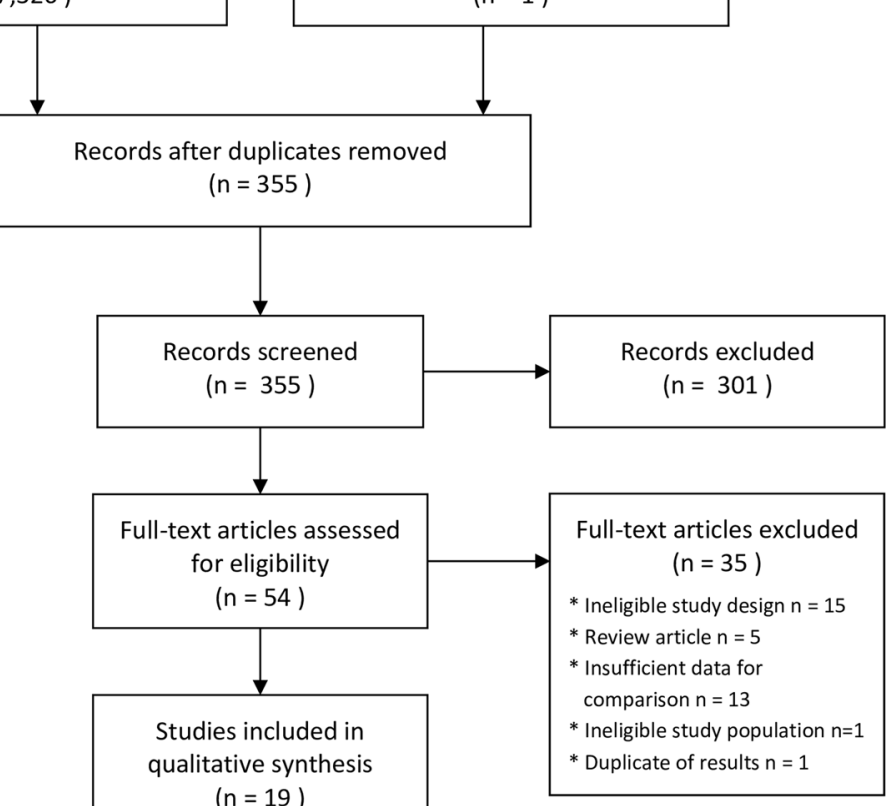

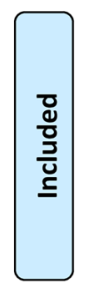

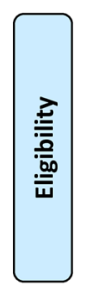
$(n=19)$

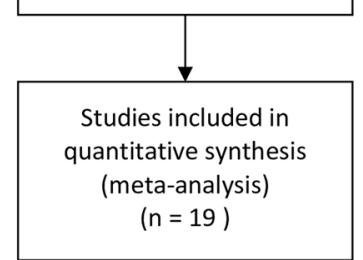

$$
\begin{aligned}
& \text { Studies included in } \\
& \text { quantitative synthesis } \\
& \text { (meta-analysis) } \\
& (n=19)
\end{aligned}
$$

Additional records identified through other sources $(n=1)$ 
Table 1 Characteristics of included studies

\begin{tabular}{|c|c|c|c|c|c|c|c|c|}
\hline \multirow[t]{2}{*}{ Study } & \multirow[t]{2}{*}{ Country } & \multirow[t]{2}{*}{ Study design } & \multicolumn{3}{|c|}{ DM group } & \multicolumn{3}{|c|}{ Non-DM group } \\
\hline & & & No & Age & Sex, male & No & Age & Sex, male \\
\hline $\begin{array}{l}\text { Acharya D et al. } \\
\text { [12] }\end{array}$ & Korea & $\begin{array}{l}\text { Multi-center cross- } \\
\text { sectional study }\end{array}$ & 55 & $69.8 \pm 13.5$ & $20(36.4 \%)$ & 269 & $51.9 \pm 21.4$ & $115(42.8 \%)$ \\
\hline Al-Salame et al. [13] & France & $\begin{array}{l}\text { Observational } \\
\text { cohort }\end{array}$ & 115 & $72.6 \pm 3.3$ & $73(62.6 \%)$ & 317 & $72.3 \pm 4.2$ & $165(52.1 \%)$ \\
\hline Alzaid et al. [14] & France & $\begin{array}{l}\text { Observational } \\
\text { cohort }\end{array}$ & 30 & $64.8 \pm 6.6$ & $23(76.7 \%)$ & 15 & $63.3 \pm 7.2$ & $8(53.3 \%)$ \\
\hline $\begin{array}{l}\text { Chung SM. et al. } \\
\text { [15] }\end{array}$ & South Korea & $\begin{array}{l}\text { Retrospective cohort } \\
\text { study }\end{array}$ & 29 & $66.3 \pm 8.9$ & $14(48.3 \%)$ & 81 & $53.5 \pm 17.9$ & $34(24.0 \%)$ \\
\hline Conway J. et al. [16] & UK & $\begin{array}{l}\text { Retrospective case } \\
\text { series }\end{array}$ & 16 & NS & $9(56.3 \%)$ & 55 & NS & $32(58.2 \%)$ \\
\hline Fox T. et al. [17] & USA & $\begin{array}{l}\text { Retrospective obser- } \\
\text { vational study }\end{array}$ & 166 & $66.42 \pm 12.67$ & $86(51.8 \%)$ & 189 & $66.03 \pm 15.46$ & $88(46.6 \%)$ \\
\hline Guan Wj. et al. [18] & China & $\begin{array}{l}\text { Multi-center retro- } \\
\text { spective case study }\end{array}$ & 130 & $61.2 \pm 13.4$ & $76 / 129(58.9 \%)$ & 1460 & $47.8 \pm 16.1$ & $828 / 1449(57.1 \%)$ \\
\hline Kim MK. et al. [19] & Korea & $\begin{array}{l}\text { Multi-center, retro- } \\
\text { spective, observa- } \\
\text { tional study }\end{array}$ & 235 & $68.3 \pm 11.9$ & $106(45.1 \%)$ & 235 & $69.7 \pm 12.4$ & $95(40.4 \%)$ \\
\hline Liang JJ. et al. [20] & China & Retrospective study & 55 & $62.4 \pm 7.7$ & $27(49.1 \%)$ & 76 & $63.3 \pm 8.3$ & $43(56.6 \%)$ \\
\hline Liu D. et al. [21] & China & $\begin{array}{l}\text { Retrospective obser- } \\
\text { vational study }\end{array}$ & 19 & $60.3 \pm 11.9$ & $10(52.6 \%)$ & 76 & $46.5 \pm 17.2$ & $36(47.4 \%)$ \\
\hline Liu Z. et al. [22] & China & $\begin{array}{l}\text { Retrospective obser- } \\
\text { vational study }\end{array}$ & 139 & $64.5 \pm 10.0$ & $66(47.5 \%)$ & 795 & $61.6 \pm 14.5$ & $388(48.8 \%)$ \\
\hline Saeed O. et al. [23] & USA & Retrospective study & 2266 & $67.9 \pm 12.8$ & $1189(52.5 \%)$ & 1986 & $61.1 \pm 17.6$ & $1066(53.7 \%)$ \\
\hline Shang J. et al. [24] & China & $\begin{array}{l}\text { Retrospective, } \\
\text { single-center } \\
\text { cohort study }\end{array}$ & 84 & NS & $42(50.0 \%)$ & 500 & NS & $235(47.0 \%)$ \\
\hline $\begin{array}{l}\text { Soliman A. et al. } \\
\text { [25] }\end{array}$ & Qatar & Retrospective study & 56 & $52.1 \pm 12.67$ & NS & 243 & $36.22 \pm 11.43$ & NS \\
\hline Wu D. et al. [26] & China & Retrospective study & 16 & $43.5 \pm 17.8$ & $8(50.0 \%)$ & 47 & $51.0 \pm 12.6$ & $25(53.1 \%)$ \\
\hline Wu J. et al. [27] & China & Retrospective study & 22 & $52.55 \pm 13.70$ & $16(72.73)$ & 44 & $47.98 \pm 15.11$ & $28(63.64 \%)$ \\
\hline Xu Z. et al. [28] & China & Retrospective study & 114 & $65.5 \pm 2.7$ & $62(54.4 \%)$ & 250 & $63.3 \pm 3.5$ & $144(57.6 \%)$ \\
\hline Zhang Y. et al. [29]a & China & Retrospective study & 63 & $64.5 \pm 4.0$ & $38(60.3 \%)$ & 195 & $63.3 \pm 2.5$ & $100(51.3 \%)$ \\
\hline Zhang Y. et al. [30]b & China & Retrospective study & 61 & $65.6 \pm 11.4$ & $33(54.1 \%)$ & 84 & $59.4 \pm 16.0$ & $41(48.8 \%)$ \\
\hline \multicolumn{3}{|c|}{ Summary characteristics } & 3671 & $66.9 \pm 12.5$ & $1898 / 3614(52.5 \%)$ & 6917 & $67.5 \pm 17.5$ & $3471 / 6663(52.1 \%)$ \\
\hline
\end{tabular}

$D M$ Diabetes mellitus; NS Not specified

studies were performed in China [18, 20-22, 24, 26-31], two in USA [17, 23], two in France [13, 14], two in Korea $[12,19]$, one in each of the following countries: UK [16], Qatar [25], and South Korea [15]. Detailed characteristics of the patients included in the meta-analysis are presented in Supplementary Digital File. The detailed risk of bias abuts the methodological quality of the included studies that are elaborated and summarized, respectively, in Table 1.

\section{Meta-analysis results}

Fourteen studies reported in-hospital mortality [12, 13, $15-19,21,22,24,25,28-30]$. The mortality of DM vs nonDM patients was 21.3 versus $6.1 \%$, respectively $(\mathrm{OR}=2.39$; 95\%CI: $1.65,3.46 ; I^{2}=62 \% ; P<0.001$; Fig. 2). We find medium effect of power analysis of in-hospital mortality (d Cohena $=0.68,95 \%$ CI: $0.51,0.72$ ).

Severe disease between DM and non-DM groups was reported in six studies [18, 19, 22, 27, 29, 30]. Severe disease in DM and non-DM group varied and amounted to 34.8 versus $22.8 \%\left(\mathrm{OR}=1.43 ; 95 \% \mathrm{CI}: 0.82,2.50 ; I^{2}=85 \%\right.$; $P=0.20)$. Clinical condition in DM group was observed in $18.4 \%$ and was higher than in non-DM group $(6.9 \%$; OR $=2.56 ; 95 \%$ CI: $1.77,3.68 ; I^{2}=0 \% ; P<0.001$; Fig. 3$)$.

In the DM group, the complications were observed more often when compared with non-DM group (Fig. 4), both in acute respiratory distress ( 31.4 vs. $17.2 \%$; $\mathrm{OR}=2.38$; 95\% CI: $\left.1.80,3.13 ; I^{2}=40 \% ; P<0.001\right)$, acute cardiac injury (22.0 vs. $12.8 \%$; OR $=2.59 ; 95 \% \mathrm{CI}: 1.81,3.73 ; I^{2}=57 \%$; $P<0.001)$, as well as acute kidney injury (19.1 vs. $10.2 \%$; 


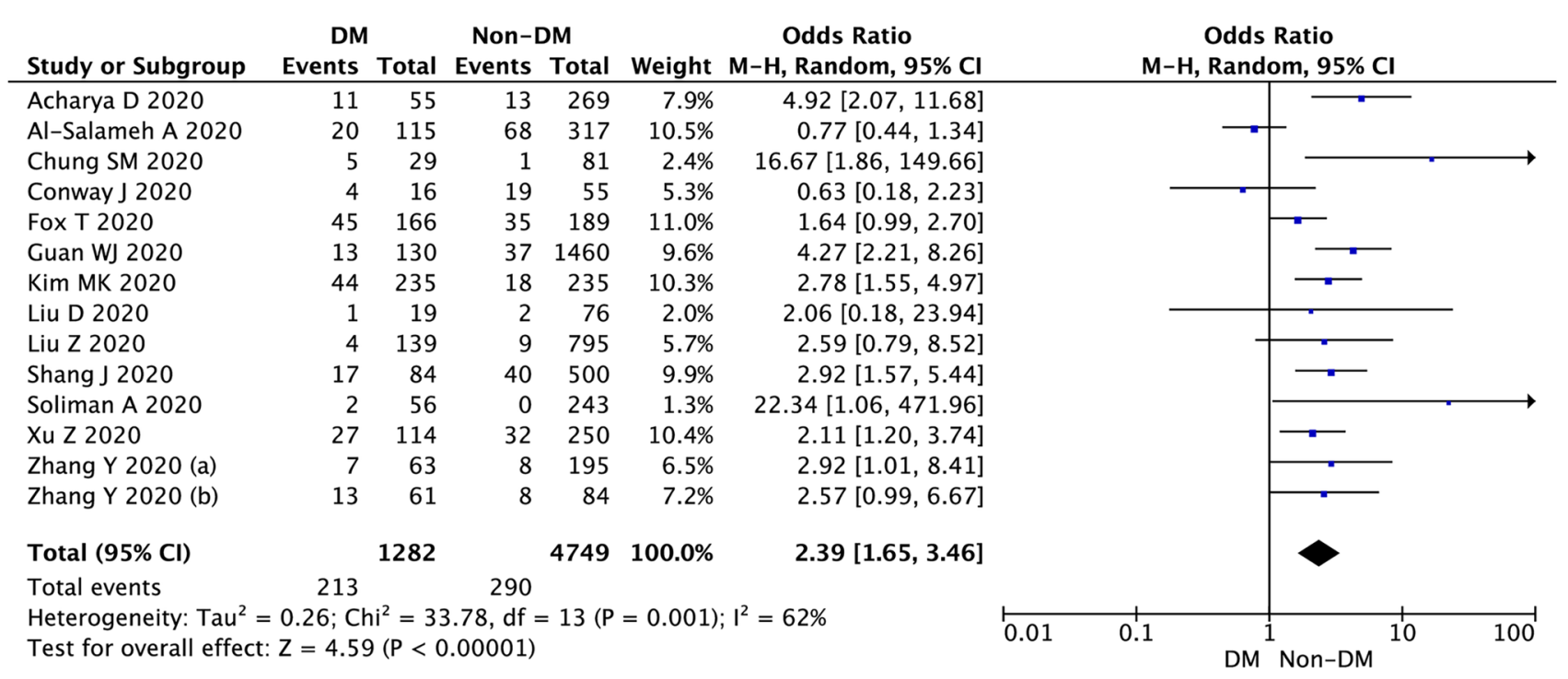

Fig. 2 Forest plot of In-hospital mortality in DM versus non-DM group. The center of each square represents the weighted odds ratios for individual trials, and the corresponding horizontal line stands for a $95 \%$ confidence interval. The diamonds represent pooled results. $D M$ Diabetes mellitus; $C I$ Confidence interval; $M-H$ Mantel-Haenszel model

complications and require more interventions including respiratory support.

Although most patients infected with COVID-19 are asymptomatic or develop only mild symptoms [33], some patients require hospitalization and even treatment in the Intensive Care Unit conditions. Diabetes has been found to be a fairly comorbidity in patients requiring ICU support ranging from 17 [34] to $32 \%$ [35], indicating the need for a diligent blood glucose monitoring [36].

Diabetes induces immunosuppression which leaves patients susceptible to develop far more severe course of infection [6]. In the cohort study by Kim et al. [37], patients who suffered from diabetes had a considerably higher incidence of infection-related hospitalizations and deaths than the general population. Similarly, in a cohort study from Saudi Arabia, patients with diabetes had a corresponding increasingly increased risk of complicated clinical course and death [38].

Importantly when discussing complication, one cannot forget that as the number of complications increases so does the financial burden of the treatment [39]. Taking into the account that the total cost of the COVID-19 management amounts to over 1.6 trillion US dollars [40], it is important to identify the factors that increase the cost of treatment in order to reduce them. The risk of admission to the ICU for the diabetic patients relies heavily on the glycemic control. For DM1 patients who achieve good control, the risk increases almost threefold, while for the patients who achieve poor control, the relative risk increases almost fivefold. The numbers are lower for the DM2 patients, and the risk increases twofold for the good 


\begin{tabular}{|c|c|c|c|c|c|c|c|c|c|}
\hline Study or Subgroup & $\begin{array}{r}\text { DM } \\
\text { Events }\end{array}$ & Total & $\begin{array}{l}\text { Non-D } \\
\text { Events }\end{array}$ & $\begin{array}{l}\text { DM } \\
\text { Total }\end{array}$ & \multirow[t]{2}{*}{ Weight } & Odds Ratio & \multicolumn{3}{|c|}{$\begin{array}{l}\text { Odds Ratio } \\
\text { M-H, Random, } 95 \% \mathrm{Cl}\end{array}$} \\
\hline \multicolumn{9}{|c|}{ 3.1.1 Mild to moderate } & \\
\hline Liu Z 2020 & 80 & 139 & 497 & 795 & $9.4 \%$ & $0.81[0.56,1.17]$ & & & \\
\hline Zhang Y 2020 (a) & 18 & 63 & 69 & 195 & $8.0 \%$ & $0.73[0.39,1.36]$ & & & \\
\hline $\begin{array}{l}\text { Zhang Y } 2020(\mathrm{~b}) \\
\text { Subtotal }(95 \% \mathrm{Cl})\end{array}$ & 9 & $\begin{array}{r}61 \\
263\end{array}$ & 19 & $\begin{array}{r}84 \\
1074\end{array}$ & $\begin{array}{r}6.5 \% \\
23.9 \%\end{array}$ & $\begin{array}{l}0.59[0.25,1.42] \\
0.76[0.57,1.03]\end{array}$ & & & \\
\hline \multicolumn{10}{|c|}{$\begin{array}{l}\text { Heterogeneity: } \text { Tau }^{2}=0.00 ; \mathrm{Chi}^{2}=0.46, \mathrm{df}=2(\mathrm{P}=0.79) ; \mathrm{I}^{2}=0 \% \\
\text { Test for overall effect: } \mathrm{Z}=1.77(\mathrm{P}=0.08)\end{array}$} \\
\hline \multicolumn{10}{|l|}{ 3.1.2 Severe } \\
\hline Guan WJ 2020 & 45 & 130 & 209 & 1460 & $9.2 \%$ & $3.17[2.15,4.68]$ & & & \\
\hline Kim MK 2020 & 65 & 235 & 45 & 235 & $9.0 \%$ & $1.61[1.05,2.49]$ & & & \\
\hline Liu Z 2020 & 53 & 139 & 235 & 795 & $9.3 \%$ & $1.47[1.01,2.14]$ & & & \\
\hline Wu J 2020 & 7 & 22 & 4 & 44 & $4.3 \%$ & $4.67[1.19,18.26]$ & & & \\
\hline Zhang Y 2020 (a) & 24 & 63 & 92 & 195 & $8.2 \%$ & $0.69[0.39,1.23]$ & & - & \\
\hline $\begin{array}{l}\text { Zhang Y } 2020(b) \\
\text { Subtotal }(95 \% \mathrm{Cl})\end{array}$ & 32 & $\begin{array}{r}61 \\
650\end{array}$ & 57 & $\begin{array}{r}84 \\
2813\end{array}$ & $\begin{array}{r}7.6 \% \\
47.7 \%\end{array}$ & $\begin{array}{l}0.52[0.26,1.03] \\
1.43[0.82,2.50]\end{array}$ & & & \\
\hline \multicolumn{10}{|c|}{$\begin{array}{l}\text { Heterogeneity: } \mathrm{Tau}^{2}=0.38 ; \mathrm{Chi}^{2}=33.02, \mathrm{df}=5(\mathrm{P}<0.00001) ; \mathrm{I}^{2}=85 \% \\
\text { Test for overall effect: } \mathrm{Z}=1.27(\mathrm{P}=0.20)\end{array}$} \\
\hline \multicolumn{10}{|l|}{ 3.1.3 Critical } \\
\hline Liu Z 2020 & 6 & 139 & 17 & 795 & $6.1 \%$ & $2.06[0.80,5.33]$ & & & \\
\hline Shang J 2020 & 17 & 84 & 50 & 500 & $8.1 \%$ & $2.28[1.24,4.19]$ & & & \\
\hline Zhang Y 2020 (a) & 21 & 63 & 34 & 195 & $7.9 \%$ & $2.37[1.25,4.50]$ & & & \\
\hline $\begin{array}{l}\text { Zhang Y } 2020(b) \\
\text { Subtotal }(95 \% \mathrm{Cl})\end{array}$ & 20 & $\begin{array}{r}61 \\
347\end{array}$ & 8 & $\begin{array}{r}84 \\
1574\end{array}$ & $\begin{array}{r}6.4 \% \\
28.4 \%\end{array}$ & $\begin{array}{r}4.63[1.88,11.44] \\
2.56[1.77,3.68]\end{array}$ & & & \\
\hline \multicolumn{10}{|c|}{$\begin{array}{l}\text { Heterogeneity: } \mathrm{Tau}^{2}=0.00 ; \mathrm{Chi}^{2}=2.06, \mathrm{df}=3(\mathrm{P}=0.56) ; \mathrm{I}^{2}=0 \% \\
\text { Test for overall effect: } \mathrm{Z}=5.03(\mathrm{P}<0.00001)\end{array}$} \\
\hline Total $(95 \% \mathrm{Cl})$ & & 1260 & & 5461 & $100.0 \%$ & $1.45[1.00,2.09]$ & & & \\
\hline Total events & 397 & & 1336 & & & & & & \\
\hline $\begin{array}{l}\text { Heterogeneity: } \text { Tau }^{2}= \\
\text { Test for overall effect: } \\
\text { Test for subgroup diff }\end{array}$ & $\begin{array}{l}0.35 ; C h \\
Z=1.96 \\
\text { ferences: }\end{array}$ & $\begin{array}{l}\mathrm{hi}^{2}=63 \\
(\mathrm{P}=0 \\
\mathrm{Chi}^{2}=\end{array}$ & $\begin{array}{l}3.22, \mathrm{df}= \\
0.05) \\
25.48, \mathrm{df}\end{array}$ & $=12(\mathrm{P}$ & $<0.0000$ & $\begin{array}{l}01) ; I^{2}=81 \% \\
001), I^{2}=92.2 \%\end{array}$ & 0.05 & $\mathrm{DM}^{1}$ Non-DM & 20 \\
\hline
\end{tabular}

Fig. 3 Forest plot of clinical conditions in DM versus non-DM group. The center of each square represents the weighted odds ratios for individual trials, and the corresponding horizontal line stands for

control and fourfold for the poor control. [41, 42]. The average cost for the DM patients as calculated by Bain et al. [43] was EUR 25,018 among people with type 2 diabetes in good glycemic control to EUR 57,244 among people with type 1 diabetes in poor glycemic control, reflecting higher risk of intensive care, ventilator support and longer hospital stay according to diabetes category, while the corresponding cost for people without diabetes was estimated at EUR 16,993, indicating the need for closer management in terms of monitoring the glucose levels of the patients. However, due to pandemic the routine followup course has been disrupted and the number of visits drastically reduced [44]. Therefore, the remote visits have emerged as a mean to replace the need for face-to-face visits [45]. Interestingly, although initiated in the "time of the crisis", it allowed for an introduction of the mechanisms that does not require personal contact and interestingly even in high-risk patients reduce the probability a $95 \%$ confidence interval. The diamonds represent pooled results. $D M$ Diabetes mellitus; $C I$ Confidence interval; $M-H$ Mantel-Haenszel model

of experiencing acute complications, resulting in lower numbers of hospitalizations and intensive treatment. [46]

A review by Klekotka et al. proved that diabetes not only increases the risk of acquiring respiratory tract infection but also leads to higher incidence of hospitalizations [47]. The main marker that is continuously tracked during treatment of diabetes is blood glucose level [48]. The number of excursions both in terms of hypo- and hyperglycemia correlates with the increased risk of complications and mortality in the patients who do not suffer from infectious disease [49]. In turn, the presence of increased fasting blood glucose level $>126 \mathrm{mg} / \mathrm{dl}$ during the SARS infection was correlated with the increase in risk of death more than threefold [50]. The population particularly affected by the COVID-19 hyperglycemia are older people as demonstrated by Xue et al. [51] as it seems that this population has an increased risk of hyperglycemia occurrence overall. Interestingly, a meta-analysis by 
Fig. 4 Forest plot of adverse events in DM versus non-DM group. The center of each square represents the weighted odds ratios for individual trials, and the corresponding horizontal line stands for a $95 \%$ confidence interval. The diamonds represent pooled results. $D M$ Diabetes mellitus; $C I$ Confidence interval; $M-H$ Mantel-Haenszel model

Table 2 Treatment characteristics in patients with diabetes versus patients without diabetes

\begin{tabular}{|c|c|c|c|c|c|c|}
\hline \multirow[t]{2}{*}{ Parameter } & \multirow{2}{*}{$\begin{array}{l}\text { Number of } \\
\text { studies }\end{array}$} & \multicolumn{2}{|l|}{ Incidence ratio } & \multirow[t]{2}{*}{ OR $(95 \% \mathrm{CI})$} & \multirow[t]{2}{*}{$P$-value } & \multirow[t]{2}{*}{$\mathrm{I}^{2}$ statistic } \\
\hline & & DM & non-DM & & & \\
\hline High-flow oxygen & 3 & $47 / 327(14.4 \%)$ & $53 / 511(10.4 \%)$ & $1.47(0.94,2.28)$ & 0.09 & 0 \\
\hline Noninvasive ventilation & 2 & $18 / 124(14.5 \%)$ & $23 / 279(8.2 \%)$ & $1.92(0.99,3.74)$ & 0.05 & 0 \\
\hline Invasive mechanical ventilation & 8 & $148 / 824(17.9 \%)$ & $164 / 2987(5.5 \%)$ & $3.13(1.96,5.00)$ & $<0.001$ & 62 \\
\hline ECMO & 3 & $14 / 327(4.3 \%)$ & $4 / 511(0.8 \%)$ & $4.75(1.63,13.85)$ & 0.004 & 0 \\
\hline Continous renal replacement therapy & 3 & $19 / 325(5.8 \%)$ & $4 / 400(1.0 \%)$ & $5.58(1.96,15.90)$ & 0.001 & 0 \\
\hline
\end{tabular}

CI Confidence interval; DM Diabetes mellitus; ECMO Extracorporeal membrane oxygenation; OR Odds ratio

Miller et al. [52] revealed that the prevalence of diabetes increases the mortality, while comorbidities do not affect the overall number of deaths. The same findings have been observed by Shang [53], whose team goes as far as to conclude that not only the diabetic patients shall avoid exposure to COVID-19 but also when treated they should be monitored more closely with special attention to improve prognosis. 


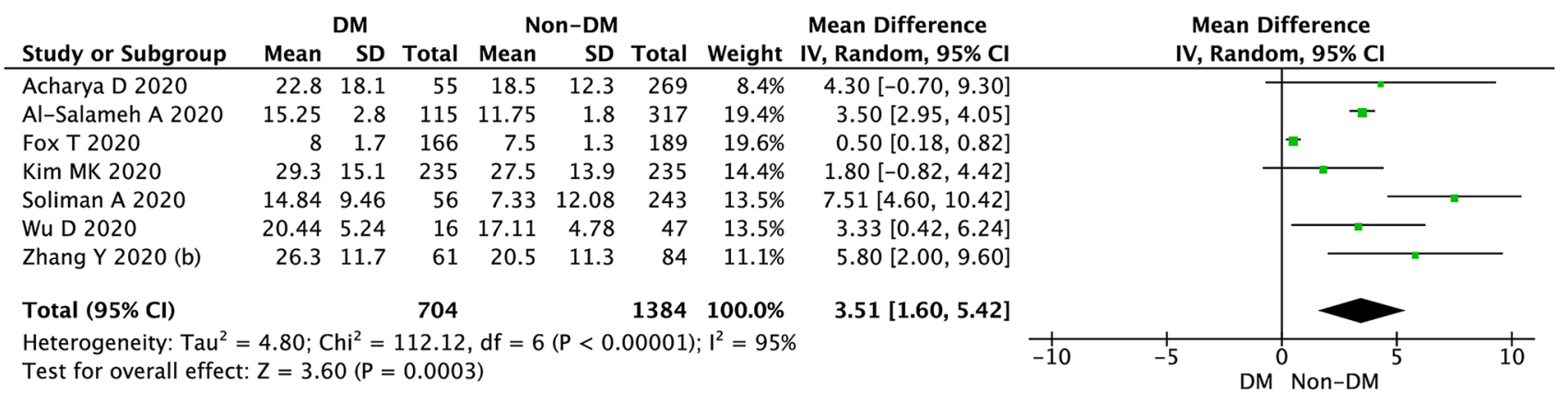

Fig. 5 Forest plot of length of hospital stay in DM versus non-DM group. The center of each square represents the weighted mean differences for individual trials, and the corresponding horizontal line

\section{Conclusions}

Based on the findings, we shall conclude that diabetes is an independent risk factor of the severity of COVID-19 in-hospital settings; therefore, patients with diabetes shall aim to reduce the exposure to the potential infection of COVID-19.

Supplementary Information The online version contains supplementary material available at https://doi.org/10.1007/s00592-021-01701-1.

Authors' contribution Conceptualization was contributed by HK, LS; Data curation was contributed by HK, WW, LS; Formal analysis was contributed by AS, LS; Project administration was contributed by HK, LS, PJC; Software was contributed by AS, LS; Supervision was contributed by MJJ, LS; Visualization was contributed by AS, HK; Writing — original draft was contributed by HK, WG, LS; Writingreview \& editing was contributed by all authors.

Funding This research did not receive any specific grant from funding agencies in the public, commercial, or not-for-profit sectors.

\section{Declarations}

Conflict of interest The authors declare that they have no conflict of interest.

\section{References}

1. Bornstein SR, Rubino F, Khunti K et al (2020) Practical recommendations for the management of diabetes in patients with COVID-19. Lancet Diabetes Endocrinol 8(6):546-550. https:// doi.org/10.1016/S2213-8587(20)30152-2

2. Dzieciatkowski T, Szarpak L, Filipiak KJ, Jaguszewski M, Ladny JR, Smereka J (2020) COVID-19 challenge for modern medicine. Cardiol J 27(2):175-183. https://doi.org/10.5603/CJ.a2020.0055

3. Fan L, Jiang S, Yang X, Wang Z, Yang C (2020) COVID-19 Drug Treatment in China. Curr Pharmacol Rep. https://doi.org/10.1007/ s40495-020-00218-5

4. Khuroo MS, Khuroo M, Khuroo MS, Sofi AA, Khuroo NS (2020) COVID-19 vaccines: a race against time in the middle stands for a $95 \%$ confidence interval. The diamonds represent pooled results. DMDiabetes mellitus; $C I$ Confidence interval; $M-H$ MantelHaenszel model

of death and devastation! J Clin Exp Hepatol 10(6):610-621. https://doi.org/10.1016/j.jceh.2020.06.003

5. Silink M (2007) A United Nations resolution on diabetes-the result of a joint effort. US Endocrinol 00(01):12. https://doi.org/ 10.17925/use.2007.00.1.12

6. Luo B, Chan WF, Lord SJ, Nanji SA, Rajotte RV, Shapiro AM, Anderson CC (2007) Diabetes induces rapid suppression of adaptive immunity followed by homeostatic T-cell proliferation. Scand J Immunol 65(1):22-31. https://doi.org/10.1111/j. 1365-3083.2006.01863.x

7. Chen Y, Gong X, Wang L, et al. Effects of hypertension, diabetes and coronary heart disease on COVID-19 diseases severity: a systematic review and meta-analysis. medRxiv. Doi:https:// doi.org/10.1101/2020.03.25.20043133

8. Ganesan SK, Venkatratnam P, Mahendra J et al (2020) Increased mortality of COVID-19 infected diabetes patients: role of furin proteases. Int J Obes (Lond) 44(12):2486-2488. https://doi.org/ 10.1038/s41366-020-00670-9

9. Moher D, Shamseer L, Clarke M et al (2015) Preferred reporting items for systematic review and meta-analysis protocols (PRISMA-P) 2015 statement. Syst Rev 4(1):1. https://doi.org/ 10.1186/2046-4053-4-1

10. Higgins JPT, Altman DG, Gøtzsche PC et al (2011) The Cochrane Collaboration's tool for assessing risk of bias in randomised trials. BMJ. https://doi.org/10.1136/bmj.d5928

11. Hozo SP, Djulbegovic B, Hozo I (2005) Estimating the mean and variance from the median, range, and the size of a sample. BMC Med Res Methodol 5:13

12. Acharya D, Lee K, Lee DS, Lee YS, Moon SS (2020) Mortality rate and predictors of mortality in hospitalized COVID-19 patients with diabetes. Healthcare (Basel) 8(3):338. https://doi. org/10.3390/healthcare8030338

13. Al-Salameh A, Lanoix JP, Bennis Y et al (2020) Characteristics and outcomes of COVID-19 in hospitalized patients with and without diabetes. Diabetes Metab Res Rev. https://doi.org/10. 1002/dmrr.3388

14. Alzaid F, Julla JB, Diedisheim M et al (2020) Monocytopenia, monocyte morphological anomalies and hyperinflammation characterise severe COVID-19 in type 2 diabetes. EMBO Mol Med. https://doi.org/10.15252/emmm.202013038

15. Chung SM, Lee YY, Ha E et al (2020) The risk of diabetes on clinical outcomes in patients with coronavirus disease 2019: a retrospective cohort study. Diabetes Metab J 44(3):405-413. https://doi.org/10.4093/dmj.2020.0105

16. Conway J, Gould A, Westley R et al (2020) Characteristics of patients with diabetes hospitalised for COVID-19 infection-a 
brief case series report. Diabetes Res Clin Pract. https://doi.org/ 10.1016/j.diabres.2020.108460

17. Fox T, Ruddiman K, Lo KB et al (2020) The relationship between diabetes and clinical outcomes in COVID-19: a single-center retrospective analysis. Acta Diabetol. https://doi.org/10.1007/ s00592-020-01592-8

18. Guan WJ, Liang WH, Zhao Y et al (2020) Comorbidity and its impact on 1590 patients with COVID-19 in China: a nationwide analysis. Eur Respir J 55(5):2000547. https://doi.org/10.1183/ 13993003.00547-2020

19. Kim MK, Jeon JH, Kim SW et al (2020) The clinical characteristics and outcomes of patients with moderate-to-severe coronavirus disease 2019 infection and diabetes in Daegu. South Korea Diabetes Metab J 44(4):602-613. https://doi.org/10.4093/dmj.2020. 0146

20. Liang JJ, Liu J, Chen Y et al (2020) Characteristics of laboratory findings of COVID-19 patients with comorbid diabetes mellitus. Diabetes Res Clin Pract. https://doi.org/10.1016/j.diabres.2020. 108351

21. Liu D, Lan L, Luo D et al (2020) Lymphocyte subsets with the lowest decline at baseline and the slow lowest rise during recovery in COVID-19 critical illness patients with diabetes mellitus. Diabetes Res Clin Pract. https://doi.org/10.1016/j.diabres.2020. 108341

22. Liu Z, Li J, Huang J et al (2020) Association between diabetes and COVID-19: a retrospective observational study with a large sample of 1880 cases in Leishenshan hospital, Wuhan. Front Endocrinol (Lausanne) 11:478. https://doi.org/10.3389/fendo. 2020.00478

23. Saeed O, Castagna F, Agalliu I et al (2020) Statin use and inhospital mortality in patients with diabetes mellitus and COVID19. J Am Heart Assoc. https://doi.org/10.1161/JAHA.120.018475

24. Shang J, Wang Q, Zhang $\mathrm{H}$ et al (2020) The relationship between diabetes mellitus and COVID-19 prognosis: a retrospective cohort study in Wuhan. China Am J Med. https://doi.org/10.1016/j. amjmed.2020.05.033

25. Soliman AT, Nair AP, Al Masalamani MS et al (2020) Prevalence, clinical manifestations, and biochemical data of type 2 diabetes mellitus versus nondiabetic symptomatic patients with COVID19: a comparative study. Acta Biomed. https://doi.org/10.23750/ abm.v91i3.10214

26. Wu D, Gao S (2020) Analysis of the lymphocyte count in patients with type 2 diabetes diabetic patients with coronavirus disease (COVID-19): a retrospective study in a centralized treatment center. Diabetes Res Clin Pract. https://doi.org/10.1016/j.diabr es.2020.108340

27. Wu J, Zhang J, Sun $X$ et al (2020) Influence of diabetes mellitus on the severity and fatality of SARS-CoV-2 (COVID-19) infection. Diabetes Obes Metab 22(10):1907-1914. https://doi.org/10. 1111/dom.14105

28. Xu Z, Wang Z, Wang S et al (2020) The impact of type 2 diabetes and its management on the prognosis of patients with severe COVID-19. J Diabetes. https://doi.org/10.1111/1753-0407.13084. 10.1111/1753-0407.13084

29. Zhang Y, Cui Y, Shen M et al (2020) Association of diabetes mellitus with disease severity and prognosis in COVID-19: a retrospective cohort study. Diabetes Res Clin Pract. https://doi.org/ 10.1016/j.diabres.2020.108227

30. Zhang Y, Li H, Zhang J et al (2020) The clinical characteristics and outcomes of patients with diabetes and secondary hyperglycaemia with coronavirus disease 2019: a single-centre, retrospective, observational study in Wuhan. Diabetes Obes Metab 22(8):1443-1454. https://doi.org/10.1111/dom.14086

31. Dall TM, Zhang Y, Chen YJ et al (2010) The economic burden of diabetes. Health Aff (Millwood) 29(2):297-303. https://doi.org/ 10.1377/hlthaff.2009.0155
32. International Diabetes Federation. COVID-19 outbreak: guidance for people with diabetes. International Diabetes Federation; 2020. https://www.idf.org/aboutdiabetes/what-is-diabetes/covid-19-anddiabetes/1-covid-19-and-diabetes.html (Available: 20 Dec 2020)

33. Grant MC, Geoghegan L, Arbyn M et al (2020) The prevalence of symptoms in 24,410 adults infected by the novel coronavirus (SARS-CoV-2; COVID-19): a systematic review and meta-analysis of 148 studies from 9 countries. PLoS ONE. https://doi.org/ 10.1371/journal.pone.0234765

34. Grasselli G, Zangrillo A, Zanella A et al (2020) Baseline characteristics and outcomes of 1591 patients infected with SARSCoV-2 admitted to ICUs of the Lombardy Region Italy. JAMA 323(16):1574-1581. https://doi.org/10.1001/jama.2020.5394

35. Garg S, Kim L, Whitaker M et al (2020) Hospitalization rates and characteristics of patients hospitalized with laboratory-confirmed coronavirus disease 2019-COVID-NET, 14 States, March 1-30, 2020. MMWR Morb Mortal Wkly Rep 69(15):458-464. https:// doi.org/10.15585/mmwr.mm6915e

36. Hussain S, Baxi H, Chand Jamali M, Nisar N, Hussain MS (2020) Burden of diabetes mellitus and its impact on COVID-19 patients: a meta-analysis of real-world evidence. Diabetes Metab Syndr 14(6):1595-1602. https://doi.org/10.1016/j.dsx.2020.08.014

37. Kim EJ, Ha KH, Kim DJ, Choi YH (2019) Diabetes and the risk of infection: a national cohort study. Diabetes Metab J 43(6):804 814. https://doi.org/10.4093/dmj.2019.0071

38. Alanazi KH, Abedi GR, Midgley CM et al (2020) Diabetes mellitus, hypertension, and death among 32 patients with MERS-CoV infection. Saudi Arabia Emerg Infect Dis 26(1):166-168. https:// doi.org/10.3201/eid2601.190952

39. Bao X, Yang C, Fang K, Shi M, Yu G, Hu Y (2017) Hospitalization costs and complications in hospitalized patients with type 2 diabetes mellitus in Beijing. China J Diabetes 9(4):405-411. https://doi.org/10.1111/1753-0407.12428 (Epub 2016 Aug 11 PMID: 27194641)

40. Cutler DM, Summers LH (2020) The COVID-19 pandemic and the $\$ 16$ trillion virus. JAMA 324(15):1495-1496. https://doi.org/ 10.1001/jama.2020.19759

41. McKeigue PM, Weir A, Bishop J et al (2020) Rapid epidemiological analysis of comorbidities and treatments as risk factors for COVID-19 in Scotland (REACT-SCOT): a population-based case-control study. PLoS Med. https://doi.org/10.1371/journal. pmed.1003374

42. Reilev M, Kristensen KB, Pottegård A et al (2020) Characteristics and predictors of hospitalization and death in the first 11122 cases with a positive RT-PCR test for SARS-CoV-2 in Denmark: a nationwide cohort. Int J Epidemiol 49(5):1468-1481. https:// doi.org/10.1093/ije/dyaa140

43. Bain SC, Czernichow S, Bøgelund M et al (2021) Costs of COVID-19 pandemic associated with diabetes in Europe: a health care cost model. Curr Med Res Opin 37(1):27-36. https://doi.org/ 10.1080/03007995.2020.1862775

44. World Health Organization. COVID-19 significantly impacts health services for noncommunicable diseases [Internet]. 2020 [cited 2021 Feb 6]. Available from: https://www.who.int/news/ item/01-06-2020-covid-19-significantly-impacts-health-servicesfor-noncommunicable-diseases

45. Ghosh A, Gupta R, Misra A (2020) Telemedicine for diabetes care in India during COVID19 pandemic and national lockdown period: guidelines for physicians. Diabetes Metab Syndr 14(4):273-276. https://doi.org/10.1016/j.dsx.2020.04.001

46. Peters AL, Garg SK (2020) The silver lining to COVID-19: avoiding diabetic ketoacidosis admissions with telehealth. Diabetes Technol Ther 22(6):449-453. https://doi.org/10.1089/dia.2020. 0187

47. Klekotka RB, Mizgała E, Król W (2015) The etiology of lower respiratory tract infections in people with diabetes. Pneumonol 
Alergol Pol 83(5):401-408. https://doi.org/10.5603/PiAP.2015. 0065

48. American Diabetes Association (2020) Standards of medical care in diabetes-2020 Abridged for primary care providers. Clin Diabetes 38(1):10-38. https://doi.org/10.2337/cd20-as01

49. Bergman M, Chetrit A, Roth J, Dankner R (2015) Dysglycemia and long-term mortality: observations from the Israel study of glucose intolerance, obesity and hypertension. Diabetes Metab Res Rev 31(4):368-375. https://doi.org/10.1002/dmrr.2618

50. Yang JK, Feng Y, Yuan MY et al (2006) Plasma glucose levels and diabetes are independent predictors for mortality and morbidity in patients with SARS. Diabet Med 23(6):623-628. https://doi.org/ 10.1111/j.1464-5491.2006.01861.x

51. Xue T, Li Q, Zhang Q, Lin W, Wen J, Li L (2020) Blood glucose levels in elderly subjects with type 2 diabetes during COVID19 outbreak: a retrospective study in a single center. Medrixiv. https://doi.org/10.1101/2020.03.31.20048579
52. Miller LE, Bhattacharyya R, Miller AL (2020) Diabetes mellitus increases the risk of hospital mortality in patients with Covid19: systematic review with meta-analysis. Medicine (Baltimore). https://doi.org/10.1097/MD.0000000000022439

53. Shang L, Shao M, Guo Q et al (2020) Diabetes mellitus is associated with severe infection and mortality in patients with COVID-19: a systematic review and meta-analysis. Arch Med Res 51(7):700-709. https://doi.org/10.1016/j.arcmed.2020.07.005

Publisher's Note Springer Nature remains neutral with regard to jurisdictional claims in published maps and institutional affiliations. 